\title{
Mortality and Morbidity of Curative and Palliative Anticancer Treatments during the COVID-19 Pandemic: A Multicenter Population-Based Retrospective Study
}

Emad Tashkandi ( $\nabla$ tashkandi.e@kamc.med.sa )

Umm Al-Qura University College of Medicine https://orcid.org/0000-0002-0260-8947

Bassam Basulaiman

King Fahad Medical City

Abdullah Alsharm

King Fahad Medical City

Marwan Al-Hajeili

King Abdulaziz University

Faisal Alshadadi

King Abdulaziz University

Lamis Halawani

King Abdulaziz University

Mubarak Al-Mansour

King Saud bin Abdulaziz University for Health Sciences

Bushra AlQuzi

King Saud bin Abdulaziz University for Health Sciences

\section{Samar Barnawi}

King Saud bin Abdulaziz University for Health Sciences

Mohammed Alghamdi

King Saud University

Nashwa Abdelaziz

King Saud University

Ruqayya Azher

Umm Al-Qura University

Amal Alabdulwahab

King Abdullah Medical City

Research article 
Keywords: COVID-19, cancer, chemotherapy, mortality, morbidity

Posted Date: October 22nd, 2020

DOI: https://doi.org/10.21203/rs.3.rs-94458/v1

License: (c) (i) This work is licensed under a Creative Commons Attribution 4.0 International License. Read Full License 


\section{Abstract}

Background: Administration of effective anticancer treatments should continue during pandemics. However, the outcomes of curative and palliative anticancer treatments during the coronavirus disease (COVID-19) pandemic remain unclear. This study aimed to determine the 30-day mortality and morbidity of curative and palliative anticancer treatments during the COVID-19 pandemic.

Methods: This is a retrospective observational study. We included all adults with solid and hematological malignancies irrespective of cancer stage and type of anticancer treatments in five large comprehensive cancer centers in Saudi Arabia.

Results: From March 1 to June 30, 2020, we included 2504 patients for analysis. The 30-day mortality was $5.1 \%(n=127)$ for all patients receiving anticancer treatment, $1.8 \%(n=24)$ for curative intent, $8.6 \%$ $(n=103)$ for palliative intent, and $13.4 \%(n=12)$ for COVID-19 cases. The 30 -day morbidity was $28.2 \%$ $(n=705)$ for all patients, $17.9 \%(n=234)$ for curative intent, 39.3\% $(n=470)$ for palliative intent, and $75 \%$ $(n=77)$ for COVID-19 cases. The 30-day mortality significantly increased with male sex (odds ratio [OR] 2.011, 95\% confidence interval [Cl] 1.141-3.546; $p=0.016)$, body mass index $(\mathrm{BMI})<25$ (OR 1.997, 95\% Cl 1.292-3.087; $p=0.002$ ), hormone therapy (OR 6.315, 95\% Cl 0.074-2.068; $\mathrm{p}=0.001$ ), and number of cycles (OR 2.110, $\mathrm{Cl}$ 0.830-0.948; $\mathrm{p}=0.001$ ), but decreased with Eastern Cooperative Oncology Group performance status (ECOG-PS) of 0-1 (OR 0.157, 95\% Cl 0.098-0.256; $\mathrm{p}=0.001)$, stage I-II cancer (OR $0.254,95 \% \mathrm{Cl} 0.069-0.934 ; \mathrm{p}=0.039$ ), and curative intent (OR 0.217, $\mathrm{Cl} 0.106-0.443 ; \mathrm{p}=0.001$ ). Meanwhile, the 30-day morbidity significantly increased with age $>65$ years (OR 1.420, 95\% $\mathrm{Cl} 1.075-1.877 ; \mathrm{p}=0.014$ ), BMl<25 (OR 1.484, 95\% Cl 1.194-1.845; $p=0.001)$, chemotherapy (OR 1.397, 1.089-5.438; $p=0.032$ ), hormone therapy (OR 1.527, 95\% Cl 0.211-1.322; $p=0.038$ ), and immunotherapy (OR 1.859, 95\% $\mathrm{Cl} 0.648$ 4.287; $p=0.038$ ), but decreased with ECOG-PS of $0-1$ (OR 0.502, 95\% Cl 0.399-0.632; $p=0.001$ ), breast cancer (OR 0.569, 95\% Cl 0.387-0.836; $p=0.004$ ), urologic cancer (OR 0.505, 95\% Cl 0.255-0.999; $p=0.050$ ), and curative intent (OR 0.410, 95\% $\mathrm{Cl} 0.296-0.586 ; \mathrm{p}=0.001)$.

Conclusions: The mortality risk was lowest with curative treatments, and hence, such treatments should not be delayed. The morbidity risk doubled with palliative treatments and was highest among COVID-19 cases. Mortality appeared to be driven by male sex, BMl<25, hormonal therapy, and number of cycles, while morbidity increased with age $>65$ years, $B M \mid<25$, chemotherapy, hormonal therapy, and immunotherapy. Thus, oncologists need to select the most effective anticancer treatments based on the above factors.

\section{Introduction}

Over the past decades, the number of chemotherapy agents has increased, and evidence has shown that chemotherapy improves survival and cancer-related symptoms (1)'(2)'(3). Caring for cancer patients is challenging, and oncologists need to weigh the risks and benefits of anticancer treatments and identify factors that could predict mortality or morbidity to improve clinical decision-making. There are no 
universally agreed-upon benchmark figures for early mortality due to anticancer treatments. However, preliminarily establishing a mortality rate of $3-9 \%$ with a mean of $5 \%$ as a reference has allowed comparisons between different institutions (4).

Globally, as of September 12, 2020, the coronavirus disease (COVID-19) has caused $>28.5$ million confirmed cases and 916 confirmed deaths and affected 216 countries (5). Patients with cancer are susceptible to COVID-19 infections because of the immunosuppressive effect of cancer and anticancer treatments (6). Moreover, it is assumed that receiving anticancer treatments will increase the mortality risk from COVID-19. Hence, many concerns have been raised regarding the management of this specific population during the pandemic. Resource utilization and allocation during the COVID-19 pandemic have been modified by implementing strategies and creating frameworks for prioritizing anticancer treatments. For instance, in Italy, a high priority was given to patients receiving curative anticancer treatment to minimize treatment interruption (7). Hanna et al. proposed a conceptual framework for prioritizing anticancer treatments, wherein palliative chemotherapy was considered a low priority compared to curative chemotherapy (8). Another suggestion was to change the route to oral anticancer therapy without compromising oncological outcomes (9). Studies have also shown that delayed adjuvant treatment is associated with inferior survival in colon cancer (10) and breast cancer (11).

Ohe et al. retrospectively studied the risk factors for mortality in lung cancer and found that $2.3 \%$ of patients died from chemotherapy-related toxicity (12). Similarly, in small-cell lung cancer, the mortality associated with sepsis was $5 \%$, as reported by Radford et al. (13). Stephens et al. found that the mortality was $10 \%$ within 3 weeks of chemotherapy (14). Another study found that the mortality was $13 \%$ in patients with non-Hodgkin's lymphoma (15).

A proportion of patients dying within 30 days of receiving anticancer treatments may be linked to poor clinical decisions. This study aimed to determine the 30-day mortality and morbidity of curative and palliative anticancer treatments during the COVID-19 pandemic and examine possible risk factors for mortality and morbidity.

\section{Methods}

\section{Study Design and Population}

From March 1 to June 30, 2020, we retrospectively collected data of all adult cancer patients, irrespective of cancer stage and type of anticancer treatments received, in five large comprehensive cancer centers in Saudi Arabia, namely, King Abdullah Medical City in Makkah, King Fahad Medical City in Riyadh, King Abdulaziz University in Jeddah, Princess Nora Cancer Center in Jeddah, and King Saud University Oncology Center in Riyadh. The study protocol was approved by the Institutional Research Ethics Boards of the above participating centers.

The inclusion criteria were adult patients with solid or hematological tumors who were receiving anticancer treatments in the outpatient setting during the study period. Both routes of anticancer 
treatments, oral and parenteral, were included. Patients were followed up until July 30, 2020 to assess treatment outcomes. The exclusion criteria were as follows: patients who were on regular follow-up or surveillance and patients treated with other modalities such as curative surgeries, radiation treatments alone, and best supportive care.

\section{Study Procedures}

Electronic health records (EHRs) were reviewed to generate a list of patients who received at least one cycle of anticancer treatment during the study period. The list was further used by investigators to identify eligible subjects for analysis. Patients who received anticancer treatments were contacted by the investigators within 30 days of the last treatment to assess treatment outcomes. Each data entry was assigned a code number to ensure data anonymity. Other than the serial code number, patient characteristics comprised age, sex, and body mass index (BMI). Clinical characteristics included the presence of comorbidities, Eastern Cooperative Oncology Group performance status (ECOG-PS), cancer type, and cancer stage. Treatment characteristics included the protocol name, type (chemotherapy, immunotherapy, hormone therapy, or targeted therapy), route (intravenous [IV], subcutaneous [SC], or oral), intent of treatment (curative or palliative), type of curative treatment (neoadjuvant or adjuvant), line of palliative treatment (first-line, second-line, third-line, or fourth-line and beyond), and number of cycles.

The primary outcome was 30-day mortality after administration of curative and palliative anticancer treatments during the COVID-19 pandemic, which was defined as death within 30 days of the last anticancer treatment cycle (excluding road traffic accident and trauma as the cause of death). The secondary outcome was 30-day morbidity, defined as morbidity within 30 days of the last anticancer treatment cycle, which included any of the following: hospitalizations, emergency room visits, intensive care unit admissions, delay in chemotherapy and dose reduction, COVID-19 incidence, and associations between the outcome and potential prognostic variables. The data collection is described in full in Appendix 1.

The cases were reviewed by senior assistants and consultants in oncology to identify the cause of death. We calculated the national 30-day mortality rate by dividing the number of patients who received anticancer treatment within 30 days of their death by the total number of patients who received anticancer treatment during the study period. If a patient received multiple cycles of anticancer treatment during the study period, the 30-day mortality was computed using the most recent cycle. Patients receiving multiple treatments in this period were counted only once in the dataset. Data were transferred securely to be analyzed and stored in a secure place.

\section{Statistical Analysis}

All data were analyzed using the Statistical Package for the Social Sciences (SPSS) version 25. Descriptive statistics (percentage, mean, and standard deviation) were calculated for continuous variables, and frequencies for categorical variables. The chi-squared test and t-test were conducted to determine any associations between demographic, clinical, tumor, and anticancer treatment characteristics. We used logistic regression analyses to assess any associations of the explanatory 
variables with 30-day mortality and 30-day morbidity (dependent variables) and with all other variables (independent variables). As none of the variables had a missing rate of $>10 \%$, all were included in the analysis. The results of the logistic regression analyses are presented as odds ratios (ORs) and 95\% confidence intervals (Cls) that reflect the effect of each variable in our regression model. A p-value of < 0.05 was considered statistically significant.

\section{Results}

Table 1 shows the characteristics of the cancer patients. Overall, 2504 patients received anticancer treatments from March 1 to June 30, 2020. Among them, 1305 were treated with curative intent and 1195 were treated with palliative intent. In total, 2069 (83\%) were $\leq 65$ years old, 1743 (70\%) were female, 945 (37.8\%) had comorbidities, 1832 (73\%) had an ECOG-PS of 0-1, $1266(51.2 \%)$ had stage IV cancer, and 1175 (46.9\%) had breast cancer, the most common diagnosis. 
Table 1

Demographic, Clinical, Tumor, and Anticancer Treatment Characteristics

\begin{tabular}{|c|c|c|c|c|c|}
\hline \multicolumn{2}{|c|}{ Patient Characteristic } & $\begin{array}{l}\text { All Patients } \\
\mathrm{N}=2504\end{array}$ & $\begin{array}{l}\text { Curative Intent } \\
\mathrm{N}=1305(52 \%)\end{array}$ & $\begin{array}{l}\text { Palliative Intent } \\
\mathrm{N}=1195 \text { (48\%) }\end{array}$ & $\mathrm{p}$-Value \\
\hline \multirow[t]{2}{*}{ Age (years) } & $>65$ & $435(17.3)$ & $181(41.7)$ & $253(58.3)$ & \multirow[t]{2}{*}{$<0.05$} \\
\hline & $\leq 65$ & 2069 (82.7) & $1124(54.4)$ & $942(45.6)$ & \\
\hline \multirow[t]{2}{*}{ Sex } & Male & $751(30)$ & $307(41)$ & $441(59)$ & \multirow[t]{2}{*}{$<0.05$} \\
\hline & Female & $1753(70)$ & $998(57)$ & $754(43)$ & \\
\hline \multirow[t]{2}{*}{ BMI } & $<25$ & $854(34.1)$ & $367(43)$ & $486(57)$ & \multirow[t]{2}{*}{$<0.05$} \\
\hline & $\geq 25$ & $1648(65.8)$ & $937(96.9)$ & $709(43.1)$ & \\
\hline \multirow[t]{2}{*}{ Comorbidities } & Yes & $945(37.8)$ & $426(48)$ & $462(59)$ & \\
\hline & No & $1556(62.2)$ & $772(53.7)$ & $666(41)$ & \\
\hline \multirow{5}{*}{$\begin{array}{l}\text { Cause of } \\
\text { comorbidity }\end{array}$} & DM & 329 (35) & $155(47.1)$ & $174(52.9)$ & \multirow[t]{5}{*}{$<0.05$} \\
\hline & HTN & $239(25.5)$ & $128(53.6)$ & $111(46.4)$ & \\
\hline & $\mathrm{IHD}$ & $53(5.6)$ & $27(50.9)$ & $26(49.1)$ & \\
\hline & DVT & $29(2.9)$ & $15(55.6))$ & $12(44.6)$ & \\
\hline & CKD & $22(2.3)$ & $9(40.9)$ & $13(59.1)$ & \\
\hline \multirow[t]{2}{*}{ ECOG-PS } & $0-1$ & $1832(73.3)$ & $1113(60.8)$ & $717(39.2)$ & \multirow[t]{2}{*}{$<0.05$} \\
\hline & $>1$ & $668(26.7)$ & 191 (28.6) & 476 (71.4) & \\
\hline \multirow[t]{3}{*}{ Cancer stage } & $H-I I$ & $548(22.2)$ & $501(91.4)$ & $47(8.6)$ & \multirow[t]{3}{*}{$<0.05$} \\
\hline & III & $659(26.6)$ & $577(87.7)$ & $81(12.3)$ & \\
\hline & IV & $1266(51.2)$ & $200(15.8)$ & $1064(84.2)$ & \\
\hline \multirow{3}{*}{$\begin{array}{l}\text { Cancer } \\
\text { diagnosis }\end{array}$} & Breast & 1175 (46.9) & $768(65.4)$ & $407(34.6)$ & \multirow[t]{3}{*}{$<0.05$} \\
\hline & Gastrointestinal & $499(19.9)$ & $146(29.3)$ & $353(70.7)$ & \\
\hline & Hematological & $252(10.1)$ & $208(82.9)$ & $43(17.1)$ & \\
\hline \multicolumn{6}{|c|}{ Data are presented as $\mathrm{n}(\%)$. Due to rounding of values, some variables may not add up to $100 \%$. } \\
\hline \multicolumn{6}{|c|}{$\begin{array}{l}\text { BMI, body mass index; DM, diabetes mellitus; HTN, hypertension; IHD, ischemic heart disease; DVT, } \\
\text { deep vein thrombosis; CKD, chronic kidney disease; ECOG-PS, Eastern Cooperative Oncology Group } \\
\text { performance status; IV, intravenous; SC, subcutaneous; SD, standard deviation. }\end{array}$} \\
\hline
\end{tabular}




\begin{tabular}{|c|c|c|c|c|c|}
\hline \multicolumn{2}{|c|}{ Patient Characteristic } & $\begin{array}{l}\text { All Patients } \\
\mathrm{N}=2504\end{array}$ & $\begin{array}{l}\text { Curative Intent } \\
\mathrm{N}=1305(52 \%)\end{array}$ & $\begin{array}{l}\text { Palliative Intent } \\
\mathrm{N}=1195(48 \%)\end{array}$ & \multirow[t]{2}{*}{ p-Value } \\
\hline & & & & & \\
\hline & Gynecological & $173(6.9)$ & 65 (37.8) & 107 (62.2) & \\
\hline & Lung & $86(3.4)$ & $11(12.8)$ & 75 (87.2) & \\
\hline & Urological & $66(2.6)$ & $10(15.4)$ & $55(84.6)$ & \\
\hline & Other & $253(10.1)$ & $97(38.5)$ & $155(61.5)$ & \\
\hline \multirow{4}{*}{$\begin{array}{l}\text { Type of } \\
\text { therapy }\end{array}$} & Chemotherapy & 1538 (61.4) & $740(48.2)$ & 796 (51.8) & \multirow[t]{4}{*}{$<0.05$} \\
\hline & $\begin{array}{l}\text { Hormone } \\
\text { therapy }\end{array}$ & $458(18.3)$ & $363(79.3)$ & $95(20.7)$ & \\
\hline & $\begin{array}{l}\text { Targeted } \\
\text { therapy }\end{array}$ & $362(14.5)$ & $147(40.6)$ & $215(59.4)$ & \\
\hline & Immunotherapy & $85(3.4)$ & $9(10.7)$ & 75 (89.3) & \\
\hline \multirow[t]{3}{*}{ Route } & IV & $1723(68.8)$ & $831(48.3)$ & $890(51.7)$ & \multirow[t]{3}{*}{$<0.05$} \\
\hline & Oral & $688(27.5)$ & $417(60.7)$ & $270(39.3)$ & \\
\hline & SC & $91(3.6)$ & $56(61.5)$ & $35(38.5)$ & \\
\hline \multirow{3}{*}{$\begin{array}{l}\text { Type of } \\
\text { curative } \\
\text { treatment }\end{array}$} & Neoadjuvant & - & $259(20.3)$ & - & - \\
\hline & Adjuvant & - & 805 (63) & - & - \\
\hline & Not applicable & - & $214(16.7)$ & - & - \\
\hline \multirow{4}{*}{$\begin{array}{l}\text { Line of } \\
\text { palliative } \\
\text { treatment }\end{array}$} & First-line & - & - & $608(50.9)$ & - \\
\hline & Second-line & - & - & $372(31.1)$ & - \\
\hline & Third-line & - & - & $139(11.6)$ & - \\
\hline & $\begin{array}{l}\text { Fourth-line and } \\
\text { beyond }\end{array}$ & - & - & $76(6.4)$ & - \\
\hline \multicolumn{2}{|c|}{ Number of cycles (mean \pm SD) } & $5.91 \pm 9.1$ & $4.46 \pm 5.12$ & $7.50 \pm 11.85$ & $<0.05$ \\
\hline \multicolumn{6}{|c|}{ Data are presented as $n(\%)$. Due to rounding of values, some variables may not add up to $100 \%$. } \\
\hline \multicolumn{6}{|c|}{$\begin{array}{l}\text { BMI, body mass index; DM, diabetes mellitus; HTN, hypertension; IHD, ischemic heart disease; DVT, } \\
\text { deep vein thrombosis; CKD, chronic kidney disease; ECOG-PS, Eastern Cooperative Oncology Group } \\
\text { performance status; IV, intravenous; SC, subcutaneous; SD, standard deviation. }\end{array}$} \\
\hline \multicolumn{6}{|c|}{$\begin{array}{l}\text { Data are calculated using the t-test or chi-squared test, as appropriate, and expressed as mean (SD) or } \\
\mathrm{n} / \mathrm{N}(\%) \text {. }\end{array}$} \\
\hline
\end{tabular}

With regard to curative anticancer treatment characteristics, most of the patients received chemotherapy (740 patients, $48.2 \%$ ), the most common route was IV (831 patients, $48.3 \%$ ), the most common type of treatment was adjuvant (805 patients, $63 \%$ ), and patients received 4 cycles of treatment, on average. As 
with palliative treatment, most of the patients received chemotherapy (796 patients, $51.8 \%$ ), the most common route was IV (890 patients, $51.7 \%$ ), the majority of patients were on first-line treatment (608 patients, $50.9 \%$ ), and patients received 8 cycles of treatment, on average.

Table 2 summarizes the outcomes of interest. In total, 127 (5.1\%) patients died within 30 days of receiving anticancer treatments, in whom $24(1.8 \%)$ received curative anticancer treatments, while 103 (8.6\%) received palliative treatments. Among the 24 patients who received curative anticancer treatments, sepsis was the most common cause of death (11 patients, 40.7\%), whereas among the 103 patients who received palliative treatments, disease progression was the most common cause of death (61 patients, 88.4\%). Meanwhile, morbidity was evident in 705 (28.2\%) patients within 30 days of receiving anticancer treatments. Among these patients, 234 (17.9\%) had curable anticancer treatments while $470(39.3 \%)$ had palliative anticancer treatments. 
Table 2

Summary of 30-Day Mortality and Morbidity Rates and Causes

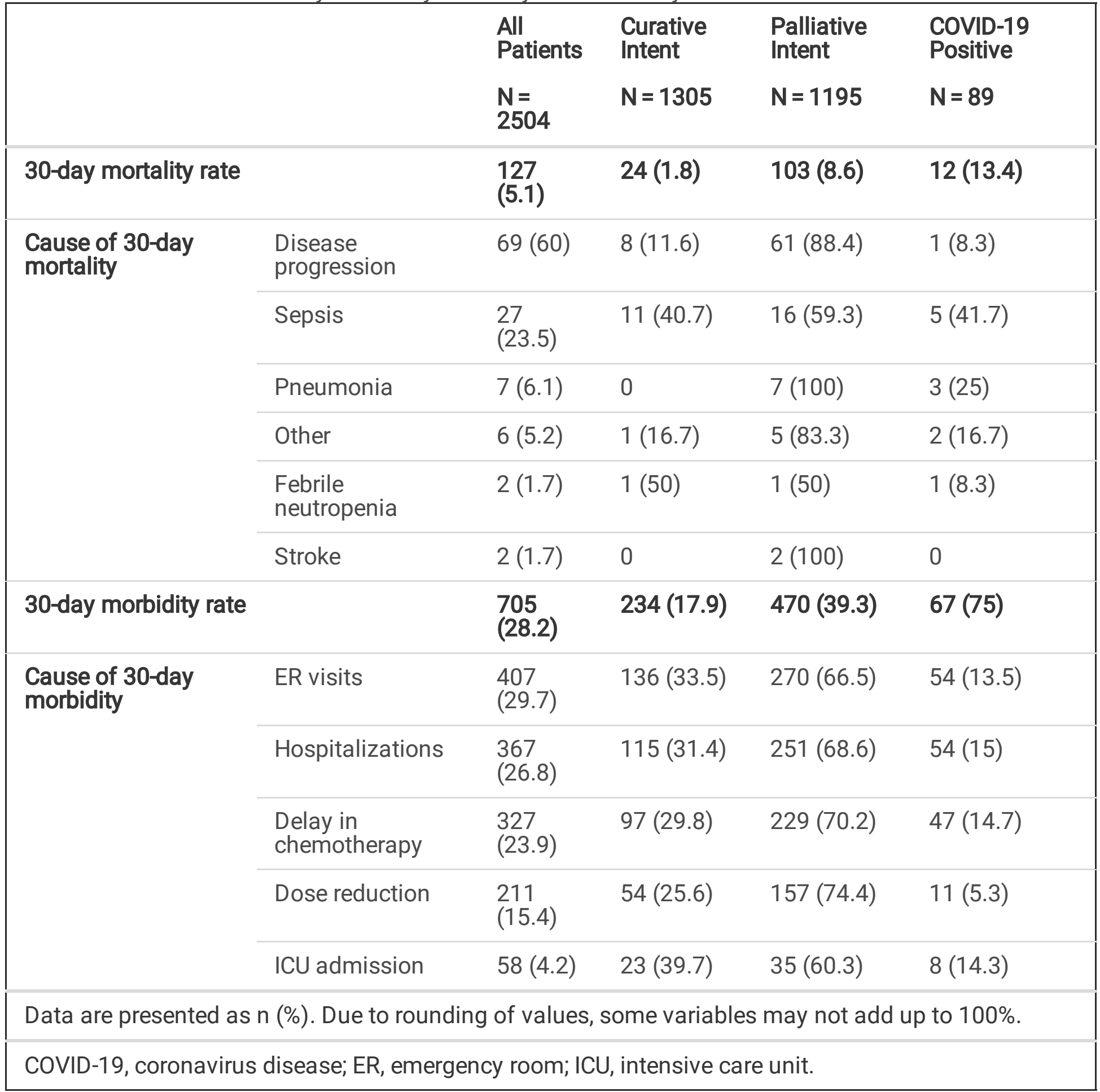

In patients who tested positive for COVID-19, the 30-day mortality was $13.4 \%(n=12)$ and the 30 -day morbidity was $75 \%(n=77)$.

Table 3 displays the results of the multivariate regression analysis of factors associated with mortality. The 30-day mortality significantly increased with male sex (OR 2.011, 95\% Cl 1.141-3.546; $\mathrm{p}=0.016$ ), $\mathrm{BMI}<25$ (OR 1.997, 95\% Cl 1.292-3.087; $\mathrm{p}=0.002)$, hormone therapy compared to targeted therapy (OR $6.315,95 \% \mathrm{Cl} 0.074-2.068 ; \mathrm{p}=0.001)$, and a greater number of cycles (OR 2.110, Cl 0.830-0.948; $\mathrm{p}=$ 0.001). However, the 30 -day mortality significantly decreased in patients with an ECOG-PS of $0-1$ (OR 
$0.157,95 \% \mathrm{Cl} 0.098-0.256 ; p=0.001)$, stage I-II cancer (OR 0.254, 95\% Cl 0.069-0.934; $\mathrm{p}=0.039$ ), and curative treatment $(\mathrm{OR} 0.217, \mathrm{Cl} 0.106-0.443 ; \mathrm{p}=0.001)$.

Table 3

Regression Analysis of Potential Prognostic Variables Associated with 30-Day Mortality

\begin{tabular}{|c|c|c|c|}
\hline & OR & p-Value & $95 \% \mathrm{Cl}$ for OR \\
\hline Age (> 65 years) & 1.053 & 0.840 & $0.636,1.745$ \\
\hline Sex (male) & 2.011 & 0.016 & $1.141,3.546$ \\
\hline BMI (<25) & 1.997 & 0.002 & $1.292,3.087$ \\
\hline ECOG-PS (0-1) & 0.157 & 0.001 & $0.098,0.253$ \\
\hline Stage IV & Reference group & 0.087 & \\
\hline Stages I-II & 0.254 & 0.039 & $0.069,0.934$ \\
\hline Stage III & 1.129 & 0.700 & $0.610,2.090$ \\
\hline Diagnosis (others) & Reference group & 0.241 & \\
\hline Breast cancer & 1.614 & 0.056 & $0.725,3.594$ \\
\hline Hematologic cancer & 2.375 & 0.926 & $0.977,5.774$ \\
\hline Gynecologic cancer & 1.033 & 0.499 & $0.523,2.041$ \\
\hline Gastrointestinal cancer & 1.405 & 0.858 & $0.524,3.764$ \\
\hline Lung cancer & 1.091 & 0.186 & $0.421,2.829$ \\
\hline Urologic cancer & 0.392 & 0.241 & $0.098,1.569$ \\
\hline Type (targeted therapy) & Reference group & 0.001 & \\
\hline Type (chemotherapy) & 2.110 & 0.062 & $0.250,3.485$ \\
\hline Type (hormone therapy) & 6.315 & 0.001 & $0.074,2.068$ \\
\hline Type (immunotherapy) & 1.239 & 0.774 & $0.262,5.253$ \\
\hline Number of cycles & 2.110 & 0.001 & $0.830,0.948$ \\
\hline Route (SC) & Reference group & 0.004 & \\
\hline Route (IV) & 1.412 & 0.596 & $0.395,5.043$ \\
\hline Route (oral) & 0.470 & 0.282 & $0.119,1.861$ \\
\hline Intention (curative) & 0.217 & 0.001 & $0.106,0.443$ \\
\hline
\end{tabular}


Table 4 shows the results of the multivariate regression analysis of factors associated with morbidity. The 30-day morbidity significantly increased with age $>65$ years (OR $1.420,95 \% \mathrm{Cl} 1.075-1.877 ; \mathrm{p}=$ $0.014), \mathrm{BMI}<25$ (OR 1.484, 95\% Cl 1.194-1.845; $\mathrm{p}=0.001)$, chemotherapy (OR 1.397, 1.089-5.438; $\mathrm{p}=$ 0.032), hormone therapy (OR 1.527, $95 \% \mathrm{Cl} 0.211-1.322 ; \mathrm{p}=0.038)$, and immunotherapy (OR $1.859,95 \%$ $\mathrm{Cl} 0.648-4.287 ; \mathrm{p}=0.038$ ). However, the 30 -day morbidity significantly decreased with an ECOG-PS of $0-$ 1 (OR 0.502, 95\% Cl 0.399-0.632; $p=0.001$ ), breast cancer (OR 0.569, 95\% Cl 0.387-0.836; $p=0.004$ ), urologic cancer (OR $0.505,95 \% \mathrm{Cl} 0.255-0.999 ; \mathrm{p}=0.050)$, a greater number of cycles (OR $0.964, \mathrm{Cl}$ $0.848-0.980 ; p=0.001)$, and curative intent (OR 0.410, $\mathrm{Cl} 0.296-0.586 ; p=0.001)$. 
Table 4

Regression Analysis of Potential Prognostic Variables Associated with 30-Day Morbidity

\begin{tabular}{|c|c|c|c|}
\hline & OR & p-Value & $95 \% \mathrm{Cl}$ for OR \\
\hline Age (> 65 years) & 1.420 & 0.014 & $1.075,1.877$ \\
\hline Sex (male) & 0.963 & 0.787 & $0.730,1.270$ \\
\hline BMI $(<25)$ & 1.484 & 0.001 & $1.194,1.845$ \\
\hline ECOG-PS (0-1) & 0.502 & 0.001 & $0.399,0.632$ \\
\hline Stage IV & Reference group & 0.210 & \\
\hline Stages I-II & 0.778 & 0.195 & $0.533,1.137$ \\
\hline Stage III & 1.058 & 0.734 & $0.765,1.461$ \\
\hline Diagnosis (others) & Reference group & 0.001 & \\
\hline Breast cancer & 0.569 & 0.004 & $0.387,0.836$ \\
\hline Hematologic cancer & 1.046 & 0.845 & $0.667,1.639$ \\
\hline Gynecologic cancer & 1.170 & 0.376 & $0.826,1.658$ \\
\hline Gastrointestinal cancer & 0.866 & 0.560 & $0.534,1.405$ \\
\hline Lung cancer & 0.763 & 0.341 & $0.438,1.331$ \\
\hline Urologic cancer & 0.505 & 0.050 & $0.255,0.999$ \\
\hline Type (targeted therapy) & Reference group & 0.077 & \\
\hline Type (chemotherapy) & 1.397 & 0.032 & $1.089,5.438$ \\
\hline Type (hormone therapy) & 1.527 & 0.038 & $0.211,1.322$ \\
\hline Type (immunotherapy) & 1.859 & 0.038 & $0.648,4.287$ \\
\hline Number of cycles & 0.964 & 0.001 & $0.948,0.980$ \\
\hline Route (SC) & Reference group & 0.001 & \\
\hline Route (IV) & 1.424 & 0.251 & $0.779,2.602$ \\
\hline Route (oral) & 0.779 & 0.437 & $0.415,1.462$ \\
\hline Intention (curative) & 0.410 & 0.001 & $0.296,0.568$ \\
\hline
\end{tabular}

Table 5 presents the incidence of COVID-19 in the study population. A total of 89 (3.6\%) patients developed COVID-19 after receiving anticancer treatments. Among them, 12 (9.5\%) patients died with within 30 days of receiving anticancer treatments, and morbidity was evident in 67 (9.7\%) patients. 
Table 5

Incidence of COVID-19 and Associations with 30-Day Mortality and Morbidity

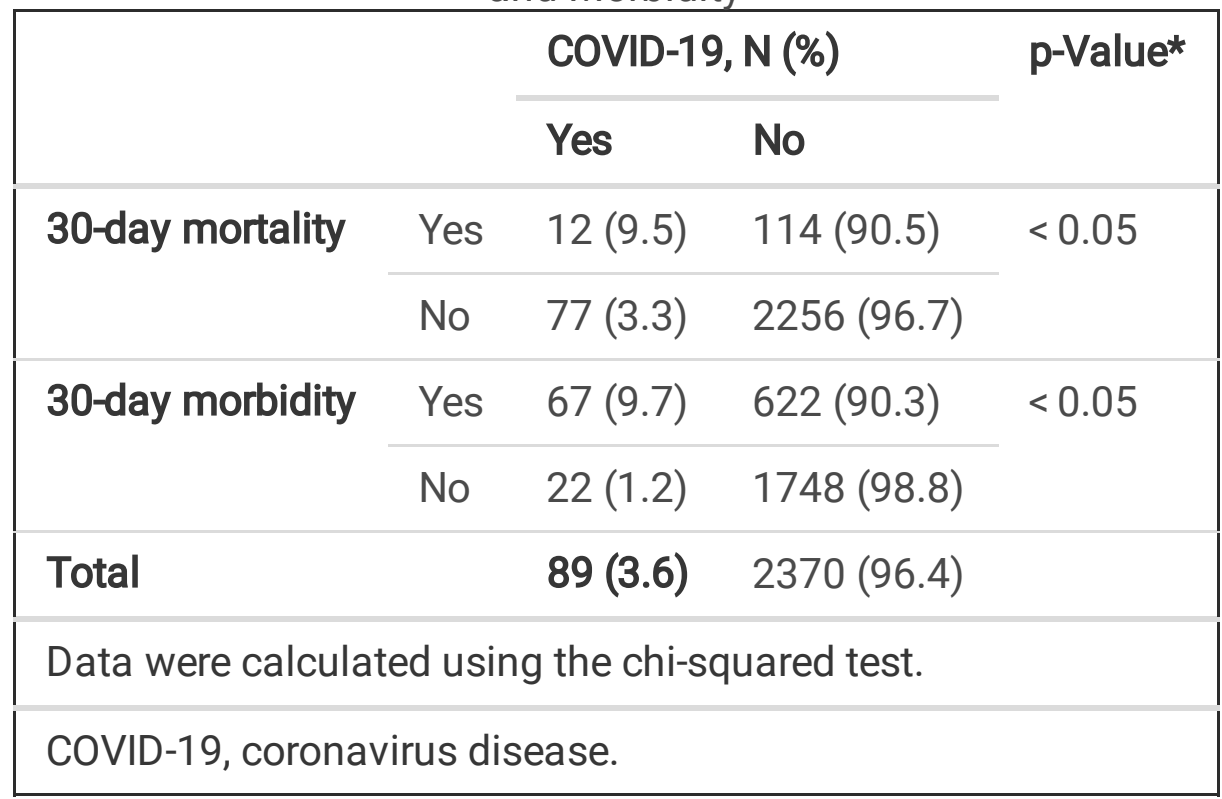

\section{Discussion}

To our knowledge, this is the first study to investigate the outcomes of curative and palliative anticancer treatments during the COVID-19 pandemic. The data were collected from large comprehensive cancer centers to support the assumption of the risks of mortality and morbidity associated with anticancer treatments during pandemics.

Our population-based study demonstrated that the 30-day mortality for all patients who received anticancer treatments was $5.1 \%$, of which $1.8 \%$ accounted for curative intent, $8.6 \%$ for palliative intent, and $13.4 \%$ for COVID-19-positive cases. The 30 -day mortality rate of $5.1 \%$ in this study could be established as a benchmark at the national level and is comparable to those reported in Australia, England, and New Zealand (5.6\%, 4\%, and 5.17\%, respectively) (16)'(17)'(18)'(19). For curative and palliative intent, we examined all patients with different cancers-unlike other studies that focused only on certain types of tumors, such as the Systemic Anti-Cancer Therapy Dataset collated by Public Health England, which reported 30 -day mortality rates of $3 \%$ and $10 \%$ for curative and palliative chemotherapy, respectively, for patients with lung cancer. For breast cancer, the 30-day mortality rates were $1 \%$ and $7 \%$ for curative and palliative chemotherapy, respectively (20). Moreover, the Royal Marsden Hospital reported 30 -day mortality rates of $0.5 \%$ and $1.5 \%$ for curative chemotherapy in breast cancers and for curative chemotherapy in GI malignancies, respectively (21).

Our study highlights that important subgroups may be at higher risk of mortality, such as male patients, those with $\mathrm{BMI}<25$, and those receiving hormone therapy. The number of cycles also significantly increased the risk of mortality. We also found that ECOG-PS 0-1, cancer stages I and II, and curative intent significantly decreased the mortality risk. For COVID-19 cases, similar to the results of the TERAVOLT registry (22), our study showed that receiving chemotherapy was associated with an 
increased mortality risk. However, the patients enrolled in the TERAVOLT registry were older, had lung cancer only, and were COVID-19 positive, unlike in our study where we included patients regardless of the cancer type and the majority of them were aged $<65$ years. Again, similar to data from the CCC19 database (23), being male and having an ECOG-PS of $\geq 2$ in this study were associated with increased 30-day mortality. Our study included all patients on active anticancer treatments, in contrast to the CCC19 database where only $39 \%$ of patients were on active anticancer treatment. Our observed mortality rate for COVID-19 was $13.4 \%$, which is comparable to that reported in China (14\%) (24), the CCC19 database (13\%) (23), and the Mount Sinai Health System (11\%) (25). However, contrary to international reports, we had a lower incidence of COVID-19 in our cohort, and this needs to be explored in future studies.

So far, no studies have described the 30-day morbidity associated with all types of anticancer treatments. Our study results showed that the 30 -day morbidity was $28.2 \%$ for all patients receiving anticancer treatments, of which $17.9 \%$ accounted for curative intent, $39.3 \%$ for palliative intent, and $75 \%$ for COVID19 cases. The factors significantly associated with an increased risk of morbidity were age $>65$ years, $\mathrm{BMI}<25$, chemotherapy, hormone therapy, and immunotherapy. We also found that a significant decrease in morbidity was associated with an ECOG-PS of $0-1$, breast cancer, urologic cancer, and curative intent of treatment. The significant increase in the 30-day morbidity of anticancer treatments suggests that oncologists should carefully consider selecting the best regimen, dose, schedule, route, and follow-up for patients receiving anticancer treatments. This must be coupled with an appropriate healthcare system and quality indicators to identify patients who need continuous support (e.g., day care, home care visit, or telemedicine), along with supportive medications to avoid potential harm.

This study has several strengths. First, we described the 30-day mortality and morbidity of curative and palliative anticancer treatments in the outpatient setting during the COVID-19 pandemic, which have not been reported previously. Second, our population was diverse in terms of age distribution, stage and type of cancer, curative and palliative intent, and presence of solid versus hematological malignancies. Lastly, we included all types of anticancer treatments such as chemotherapy, immunotherapy, targeted therapy, and hormone therapy as well as the most common routes of treatment such as IV, SC, and oral. However, there are limitations to be considered. First, the study has a retrospective design. Second, the study was restricted to Saudi Arabia, which limits the inferences that can be drawn from the findings. Third, the majority of patients were younger than 65 years and were females with breast cancer. However, we attempted to control for these factors by inviting more centers to participate, which could yield a real difference in findings between our study and those of others. Finally, there was a lower incidence of COVID-19 cases in our cohort, which might be related to patients having no or mild symptoms. Prospective cancer registries for COVID-19 cases can capture more accurate data, which would be a possible avenue for future research.

In conclusion, our findings add to previous knowledge on the outcomes of curative and palliative anticancer treatments for solid and hematological malignancies during COVID-19. Our data strongly indicated that curative intent was associated with a lower 30-day mortality than palliative intent, and COVID-19 cases had the highest risk of mortality. Additionally, mortality appeared to be driven by male 
sex, $\mathrm{BMI}<25$, hormonal therapy, and number of cycles, while morbidity doubled with palliative treatments and reached $75 \%$ with COVID-19 cases. Morbidity was driven by age $>65$ years, BMI $<25$, chemotherapy, hormonal therapy, and immunotherapy. These data support the conclusion that curative and selected palliative anticancer treatments can be safely continued, thereby reducing the burden of accumulated delays in elective cancer surgeries. Avoiding delays in treatment could relieve pressure among oncologists and maintain good oncological outcomes among cancer patients.

Our data do not necessarily suggest that curative and palliative anticancer treatments can increase the COVID-19 infection risk, as only 3.6\% $(n=89)$ out of $96.4 \%(n=2370)$ of patients developed COVID-19 infection. This may provide confidence to oncologists to continue administering anticancer treatments during pandemics so long as appropriate protective measures are undertaken along with tele-oncology care. Our study highlights the importance of informed decision-making between oncologists and cancer patients on whether to withhold or continue anticancer treatments during pandemics. This study can contribute to existing literature by providing a benchmark that can be used as a reference for comparing the mortality and morbidity rates of curative and palliative anticancer treatments.

The 30-day mortality rate after anticancer treatment might be a useful clinical indicator for most anticancer treatment protocols. Stopping or delaying anticancer treatments during pandemics can lead to adverse oncological outcomes. Hence, understanding the outcomes of curative and palliative anticancer treatments as well as the outcomes for COVID-19 is urgently needed to help in clinical decision-making.

\section{Abbreviations}

COVID-19: coronavirus disease

BMI: body mass index

Cl: confidence interval

ECOG-PS: Eastern Cooperative Oncology Group performance status

EHRs: electronic health records

IV: intravenous

OR: odds ratio

SC: subcutaneous

\section{Declarations}

\section{Funding:}

Not applicable. 


\section{Conflicts of Interest:}

None declared.

\section{Availability of Data and Material:}

Available upon request.

\section{Ethics Approval:}

This study was approved by the Institutional Research Ethics Board of all participating centers.

\section{Acknowledgments:}

We thank all senior assistants and oncologists who participated in this project. Also, we would like to thank Editage (www.editage.com) for English language editing.

\section{Authors' Contributions:}

All authors contributed significantly to the conception and design of the study, and the acquisition, analysis, and interpretation of data. All authors contributed to the drafting of the article and approved the final submitted version.

\section{References}

1. Fossati R, Confalonieri C, Torri V, Ghislandi E, Penna A, Pistotti V, et al. Cytotoxic and hormonal treatment for metastatic breast cancer: A systematic review of published randomized trials involving 31,510 women. Vol. 16, Journal of Clinical Oncology. American Society of Clinical Oncology; 1998. p. $3439-60$.

2. Morgan GW, Ward R, Barton M. The contribution of cytotoxic chemotherapy to 5-year survival in adult malignancies. Clin Oncol. 2004 Dec;16(8):549-60.

3. Chabner BA, Roberts TG. Chemotherapy and the war on cancer. Vol. 5, Nature Reviews Cancer. 2005. p. 65-72.

4. Banner R. Benchmark 30-day Mortality Rate Needed. Clin Oncol. 2009 Nov;21(9):733-4.

5. Coronavirus disease (COVID-19) [Internet]. [cited 2020 Sep 13]. Available from: https://www.who.int/emergencies/diseases/novel-coronavirus-2019

6. Shankar A, Saini D, Roy S, Mosavi Jarrahi A, Chakraborty A, Bharti SJ, et al. Cancer Care Delivery Challenges Amidst Coronavirus Disease - 19 (COVID-19) Outbreak: Specific Precautions for Cancer 
Patients and Cancer Care Providers to Prevent Spread. Asian Pac J Cancer Prev [Internet]. 2020 Mar 1 [cited 2020 Apr 8];21(3):569-73. Available from: http://www.ncbi.nlm.nih.gov/pubmed/32212779

7. Lambertini M, Toss A, Passaro A, Criscitiello C, Cremolini C, Cardone $C$, et al. Cancer care during the spread of coronavirus disease 2019 (COVID-19) in Italy: Young oncologists' perspective. ESMO Open [Internet]. 2020 Mar 30 [cited 2020 Jul 7];5(2). Available from:

https://pubmed.ncbi.nlm.nih.gov/32229501/

8. Hanna TP. Cancer, COVID-19 and the precautionary principle: prioritizing treatment during a global pandemic. Nat Rev Clin Oncol. 2020;

9. Hofheinz R-D, Wenz F, Post S, Matzdorff A, Laechelt S, Hartmann JT, et al. Chemoradiotherapy with capecitabine versus fluorouracil for locally advanced rectal cancer: a randomised, multicentre, noninferiority, phase 3 trial. Lancet Oncol. 2012 Jun;13(6):579-88.

10. Biagi JJ, Raphael MJ, Mackillop WJ, Kong W, King WD, Booth CM. Association between time to initiation of adjuvant chemotherapy and survival in colorectal cancer a systematic review and metaanalysis. Vol. 305, JAMA - Journal of the American Medical Association. American Medical Association; 2011. p. 2335-42.

11. Raphael MJ, Biagi JJ, Kong W, Mates M, Booth CM, Mackillop WJ. The relationship between time to initiation of adjuvant chemotherapy and survival in breast cancer: a systematic review and metaanalysis. Vol. 160, Breast Cancer Research and Treatment. Springer New York LLC; 2016. p. 17-28.

12. Ohe Y, Yamamoto S, Suzuki K, Hojo F, Kakinuma R, Matsumoto T, et al. Risk factors of treatmentrelated death in chemotherapy and thoracic radiotherapy for lung cancer. Eur J Cancer. 2001 Jan;37(1):54-63.

13. Radford JA, Ryder WDJ, Dodwell D, Anderson H, Thatcher N. Predicting septic complications of chemotherapy: An analysis of 382 patients treated for small cell lung cancer without dose reduction after major sepsis. Eur J Cancer. 1993;29(1):81-6.

14. Stephens RJ, Girling DJ, Machin D. Treatment-related deaths in small cell lung cancer trials: can patients at risk be identified? Medical Research Council Lung Cancer Working Party. Lung Cancer. 1994 Sep;11(3-4):259-74.

15. Gómez H, Hidalgo M, Casanova L, Colomer R, Pen DL, Otero J, et al. Risk factors for treatment-related death in elderly patients with aggressive non-Hodgkin's lymphoma: Results of a multivariate analysis. J Clin Oncol. 1998 Jun;16(6):2065-9.

16. Gilbar PJ, McPherson I, Aisthorpe GG, Kondalsamy-Chennakes S. Systemic anticancer therapy in the last 30 days of life: Retrospective audit from an Australian Regional Cancer Centre. J Oncol Pharm Pract. 2019 Apr;25(3):599-606.

17. Khoja L, McGurk A, O’Hara C, Chow S, Hasan J. Mortality within 30 days following systemic anticancer therapy, a review of all cases over a 4 year period in a tertiary cancer centre. Eur $\mathrm{J}$ Cancer. 2015 Jan;51(2):233-40.

18. Ang E, Newton LV. Thirty-day mortality after systemic anticancer treatment as a real-world, quality-ofcare indicator: the Northland experience. Intern Med J. 2018 Apr;48(4):403-8. 
19. Dahiana Pulgar B, Nicolás Yáñez B, Francisco Ortega G. Mortality within 30 days of receiving systemic chemotherapy at a regional oncology unit. Rev Med Chil. 2019;147(7):887-90.

20. Wallington M, Saxon EB, Bomb M, Smittenaar R, Wickenden M, McPhail S, et al. 30-day mortality after systemic anticancer treatment for breast and lung cancer in England: a population-based, observational study. Lancet Oncol. 2016;17(9):1203-16.

21. O'Brien MER, Borthwick A, Rigg A, Leary A, Assersohn L, Last K, et al. Mortality within 30 days of chemotherapy: A clinical governance benchmarking issue for oncology patients. $\mathrm{Br} \mathrm{J}$ Cancer. 2006;95(12):1632-6.

22. Garassino MC, Whisenant JG, Huang LC, Trama A, Torri V, Agustoni F, et al. COVID-19 in patients with thoracic malignancies (TERAVOLT): first results of an international, registry-based, cohort study. Lancet Oncol. 2020 Jul 1;

23. Kuderer NM, Choueiri TK, Shah DP, Shyr Y, Rubinstein SM, Rivera DR, et al. Clinical impact of COVID19 on patients with cancer (CCC19): a cohort study. Lancet. 2020 Jun 20;

24. Guan W, Ni Z, Hu Y, Liang W, Ou C, He J, et al. Clinical Characteristics of Coronavirus Disease 2019 in China. N Engl J Med [Internet]. 2020 Apr 30 [cited 2020 Sep 10];382(18):1708-20. Available from: http://www.nejm.org/doi/10.1056/NEJMoa2002032

25. Mehta V, Goel S, Kabarriti R, Cole D, Goldfinger M, Acuna-Villaorduna A, et al. Case Fatality Rate of Cancer Patients with COVID-19 in a New York Hospital System. Cancer Discov [Internet]. 2020 Jul 1 [cited 2020 Sep 10];10(7):935-41. Available from: https://pubmed.ncbi.nlm.nih.gov/32357994/ 